\title{
Árpád Szabó and Imre Lakatos, Or the relation between history and philosophy of mathematics
}

\section{András Máté}

Ë̈tvös Loránd University

The thirty year long friendship between Imre Lakatos and the classic scholar and bistorian of mathematics Árpád Szabó had a considerable infuence on the ideas, scholarly career and personal life of both scholars. After recalling some relevant facts from their lives, this paper will investigate Szabo's works about the history of pre-Euclidean mathematics and its philosophy. We can find many similarities with Lakatos' philosophy of mathematics and science, both in the self-interpretation of early axiomatic Greek mathematics as Szabo reconstructs it, and in the general overview Szabo provides us about the turn from the intuitive methods of Greek mathematicians to the strict axiomatic method of Euclid's Elements. As a conclusion, I will argue that the correct explanation of these similarities is that in their main works they developed ideas they had in common from the period of intimate intellectual contact in Hungarian academic life in the mid-twentieth century. In closing, I will recall some relevant features of this background that deserve further research.

The history of mathematics, lacking the guidance of philosophy has become blind, while the philosophy of mathematics, turning its

I am indebted to Alex Bellamy (London School of Economics) for sending me copies of Szabó's letters to Lakatos. I wish to thank László Vekerdi (Library of the Hungarian Academy of Sciences) and Prof. Gábor Palló (Institute for Philosophy of the Hungarian Academy of Sciences), for numerous verbal comments and suggestions, and I am especially indebted to Mrs. Klára Szabó for her valuable information and for allowing me to read and quote from some letters of Lakatos. Earlier versions of this paper have been read in the Logic Colloquium of Erlangen University in June 2003 and on the 12th International Congress of Logic, Methodology and Philosophy of Science, Oviedo, August 2003; I received several helpful comments and criticism on both occasions. I also thank the editor of this issue for help.

Perspectives on Science 2006, vol. 14, no. 3

(C) 2006 by The Massachusetts Institute of Technology 
back on the most intriguing phenomena in the history of mathematics has become empty. (Lakatos 1976, p. 2.—after Kant)

\section{Lakatos, Szabó and mathematics-biographical notes}

It is instructive to trace the highlights of the lives of Lakatos and Szabó in parallel, in order to explore reasons for similarities in their works. Árpád Szabó (1913-2001) was professor of ancient philology in the late 30's at the University of Debrecen, Faculty of Arts, while Imre Lakatos (19221974, till 1945 named Imre Lipsitz) was a student from 1940 in the Faculty of Law of the Debrecen University (although he studied mainly mathematics and philosophy). In 1943, Lakatos attended the Plato reading seminar led by Szabó, who was trained in philosophy, history and ancient philology. Soon, professor and student started a politically oriented discussion about Plato, which none of the other students were able to follow. This was the beginning of their friendship, which, in spite of several difficulties, did not break off until the death of Lakatos.

After the end of World War II, Lakatos worked in the Ministry of Culture as a confidant of the Communist party elite and continued his studies in Budapest's Eötvös Collegium in sociology, mathematics and philosophy. For a few semesters he was a teaching assistant of the mathematician Ottó Varga in Debrecen as well. During that time he persuaded Szabó to join the Communist Party, too. In 1946, Szabó became Fellow of the Eötvös Collegium, but until 1948 he also kept his position in Debrecen. At this time, Alfréd Rényi, later of world fame and Lakatos' director, became professor of mathematics in the University of Debrecen. Rényi was working on many topics including graph theory and theory of probability. He was the founder of the Institute for Applied Mathematics of the Hungarian Academy of Science. ${ }^{1}$ He became colleague of both Szabó and Lakatos. Lakatos earned his $\mathrm{PhD}$ in 1947 in Debrecen with the thesis "Socio-historical aspects of concept formation in science." Opponents at the dissertation defense were Sándor Karácsony, professor of pedagogy and the mathematician Ottó Varga. This thesis was later "lost."

In the years between 1945 and 1949 Lakatos' political career was in a steep ascent. At the same time, Lakatos and Szabó were planning to work together about the history of dialectics. Lakatos' plans were to write about modern and Szabó's to write about ancient dialectics. Lakatos has never

1. Founded in 1950 and its first director was Alfréd Rényi until his death in 1970. The Institute's name has been changed more than once; in what follows, I refer to it as Rényi Institute, its present name.

2. For a view of the history and traces of this thesis (Kutrovátz 2001). 
brought this plan to fruition, but some of Szabó's articles in the early fifties (Szabó 1953, 1954a, 1954b) can be regarded as partial realizations of it. (See more about dialectics in Szabó's work below in section 3.2.) $)^{3}$ However, both Lakatos' Proofs and Refutations and Szabó's Beginnings of Greek Mathematics have their roots in this plan, as they investigate the history of dialectics in Mathematics.

In 1949 Lakatos fell out of favor, and in 1950 he was sent as a political prisoner, without ever having been sentenced, to the notorious forced labor camp Recsk. By 1952, Szabó was expelled from the Communist Party because of his critical remarks concerning Stalin's writings on linguistics. In 1953 Lakatos was released from Recsk and thanks to Alfréd Rényi, he got a job as a librarian and later as a research fellow in the Rényi Institute. He translated György Pólya's How to Solve It? ? $^{4}$ into Hungarian and attended the seminar of László Kalmár about the foundations of mathematics. ${ }^{5}$ His meeting with Pólya's heuristics and with Kalmár's work represents the influence of the Hungarian school of mathematics on his philosophy. However, he could not kept out of politics. In October 1956

3. Szabó mentioned this idea to Gábor Palló in an unpublished interview in the nineties (kind information by Prof. Palló and Mr. Bellamy). Klára Szabó remembers it, too, and she finds it possible that some hints by both Lakatos and Szabó in their correspondence in the fifties and sixties about "the continuation of their common work" belong to this plan, too.

4. György/Georg Pólya (1887-1985) studied philosophy and law and later mathematics at the University of Budapest. In the foreword to the Hungarian edition of How to Solve It? he quotes the words of his professor of mathematical analysis Manó Beke, who after looking into his university records, told him: "I see, you are coming to mathematics from philosophy. You will return there, but don't do it too early." (Pólya 1945/1969, p. 10.) Pólya left Hungary immediately after finishing his studies in 1913 and, as he writes on the same place, he tried to follow Professor Beke's council: he earned world-wide reputation in mathematical analysis (the textbook written with his friend and Stanford colleague Gábor Szego [Pólya-Szego 1998] is in use in university education even today), but from the thirties on, he set about to elaborate his mathematical heuristics, the study of the ways of mathematical problem-solving and discovery (see futher [Pólya 1954], [Pólya 1962]) as his contribution to philosophy. This topic led him further to the problems of mathematics education. Although he kept rather few contacts with Hungary until the sixties, his work was followed with special attention. Tamás Varga has done great work for the dissemination of his ideas concerning heuristics and mathematical education (see more about T. V. below).

5. The work of László Kalmár (1905-1976) is considered to be of the highest level of foundational research from the late twenties on. He also had a vivid interest in the philosophy of mathematics. His four-volume lecture notes about the foundation of mathematics (Kalmár 1974), written in the fifties, contain long passages about philosophical questions, strictly in the spirit of Marxist-Leninism. About his philosphical views before and after the Stalinist period and about his influence on Lakatos see Dezso Gurka's paper in this issue (Gurka 2006). 
Lakatos' speech in the reform-communist Petőfi Circle ${ }^{6}$ displayed a radical change in his political and ideological views; it was a substantial contribution to the intellectual antecedents of the Hungarian revolution. In November 1956 he escaped to Austria, then emigrated to the United Kingdom to study at Cambridge with the help of a Rockefeller Fellowship obtained with the support of Gábor Szegő. He did a second Ph.D. thesis there at King's College, this time in the philosophy of Mathematics.

Up to 1955 Szabó's research work had been directed mainly to Eleatic philosophy. He started from the Parmenides-interpretation of Reinhardt and presented Parmenides and Zeno as founders of Greek dialectic and logic. In his main work The Beginnings of Greek Mathematics (Anfänge der griechischen Mathematik) (Szabó 1969/1978) he wrote that this research on Greek dialectics led him to the early history of Greek mathematics. In 1957 Szabó was fired from his professorship because of his activity in the 1956 anti-Soviet revolution (he was elected president of the revolutionary committee of the Eötvös University Budapest). His former Debrecen colleague Rényi offered him a job as a research fellow in the history of mathematics in the Rényi Institute. He kept this position until his retirement in 1983 and never got an occasion to teach until 1990, except his house seminars. Between 1956 and 1966 Szabó published eleven papers containing the basic ideas of his The Beginnings of Greek Mathematics elaborating substantial details of it. ${ }^{7}$ Lakatos refers to these papers more than once, especially to "Deiknymi, as a mathematical expression for to prove" (Deiknymi, als mathematischer Terminus für beweisen) ${ }^{8}$ (Szabó 1958). Szabó puts his basic question as the title of the first of these papers shows: "How did mathematics become a deductive science?" (Wie ist die Mathematik eine deduktive Wissenschaft geworden?).

By 1957 Lakatos began to exchange letters with Szabó. ${ }^{9}$ (They met per-

6. Published in English as "On Rearing Scholars" in (Motterlini 1999, pp. 375-82.)

7. For the details of these papers, see Szabó 1969, p. 37/1978, p. 32.

8. Deiknymi (Gr.): the first and basic meaning of this word in everyday language is to show, but it has also the following meanings: to point out, explain, prove, to make the trutb/falsity of a mathematical statement visible in some way, to reflect on it, and draw the correct conclusion from it. Szabó summarizes the core of the early Greek notion of proof on this way : "It is reflection which transforms what we see, into visible, empirical evidence" (Szabó 1969, p. 251/1978, p. 190).

9. Let me quote some words from Szabó's first answer (19. June 1957, in Hungarian): "I see with surprise that your last (first!) letter was dated just a month ago. There are only practical reasons for answering you so late, and they are not identical with your fears. . . I I would be glad, too, if we exchanged letters and informed each other about our works regularly ... I had some annoying and nerve-racking troubles in the last weeks . . " Lakatos was obviously afraid that Szabó got imprisoned. The letter informing Szabó about the dismissal from his professorship, signed by vice-minister of education and philosopher József 
sonally again in 1965.) Their correspondence continued until 1974 (the last letters are dated some days before Lakatos' death.) The letters concern Szabó's repeated efforts to find contacts with the scholarly community of the western world (Lakatos helped him do that) and the work and opinions of Hungarian mathematicians, mainly Szabó's colleagues at the Rényi Institute. The names of these mathematicians, Alfréd Rényi, László Kalmár, Pál Turán and Tamás Varga occur repeatedly in their correspondence.

Lakatos started a correspondence with Pólya in 1957, and later they had a personal contact that was of great importance for Lakatos. ${ }^{10}$ In 1961 he received his Ph.D. in Cambridge with the thesis "Essays in the logic of Mathematical Discovery." Proofs and Refutations (revised parts of the thesis) were published two years later as a series of articles in the British Journal for the Philosophy of Science. His work was mostly focused on the philosophy of mathematics until around the mid-60s when it shifted focus to the philosophy of science. But in a letter to Szabó in 1968 he promised him he would return to the former subject. ${ }^{11}$ He never published on it again, except a discussion paper with important references to Szabó. ${ }^{12}$ Szabó however continued work on ancient mathematics, and in 1969 he published Anfänge der griechischen Mathematik (The Beginnings of Greek Mathematics).

In 1969, after Popper's retirement, Lakatos was appointed Professor of Logic at the London School of Economics. He held this chair until his death in 1974.

Szigeti, was dated on the same day as this letter. All the letters quoted from Szabó are in Hungarian and to be found in the LSE Archive, supplied by Alex Bellamy and quoted with permission of Klára Szabó.

10. In the acknowledgements to his unpublished $\mathrm{PhD}$ thesis Lakatos lists as his "ideological" sources Hegel's dialectics, Poppers critical philosophy and Pólya's heuristics (see note by the editors of Lakatos 1978, p. 70). The following passage from a letter by Lakatos may be in connection with this enumeration: "Now do stop fretting about my ignoring your work! ('Az egyetlen Pólyán kívül senki más' [Nobody but Pólya alone])" (Lakatos to Szabó, in the possession of Klára Szabó, from 25. April 73, in English, except for the Hungarian quotation [probably from a letter of Szabó, although I could not find that letter yet].)

11. "I think my excursion to the philosophy of science is a necessary digression before I return to my long book about the philosophy of mathematics ... After finishing the book [The Changing Logic of Scientific Discovery] I'll return immediately to the philosophy of mathematics and this will lead to the renaissance of our friendship." (Lakatos to Szabó, 5th Oct. 1968, in the possession of Klára Szabó, in Hungarian.)

12. See (Lakatos 1978, pp. 93-103.), references on p. 99f. and the editorial remarks to this paper on p. 70. 


\section{Szabó's history of mathematics and Lakatos' philosophy of mathematics}

\subsection{Parallels}

For readers familiar with Lakatos' philosophy of mathematics and science, some parallels between it and Szabó's general views about the history of mathematics and the philosophy of Greek mathematics as he reconstructs it, should be more than obvious. Let us outline the most important similarities:

1. Mathematics is not Euclidian but quasi-empirical, ${ }^{13}$ not infallible but open to refutation and revision. For instance there is in principle no warranty for the truth of the basic hypotheses (including definitions) and there is no way to defend us a priori from contradictions and paradoxes. As a slight difference, in Szabó's picture of ancient mathematics contradictions are the potential falsifiers for a classical axiomatic theory-not counterexamples, as in Lakatos' reconstructions.

2. Mathematics is not identical with deductive-axiomatized mathematics and mathematical discovery is not identical with deductions from the axioms. Concepts, as well as theorems, have to be discovered in mathematics. Mathematics cannot be born and exist without intuitive foundations.

3. The history (or if you will: the development) of mathematics is not merely a series of discoveries of theorems, but consists of problems and more or less successful attempts to solve them. Both the solutions and the failures produce new questions and new challenges. This process is neither cumulative nor a mere temporal sequence of incommensurable views; this is a dialectical process.

\subsection{The "influence" question}

Of course, such important similarities between the works of two close friends do not emerge by pure chance. It may be asked whether Lakatos simply took over some basic principles of his philosophy from the doctrines of his older friend or whether Szabó was looking for an indirect historical support for the claims of his former student, showing that his friend's somewhat extraordinary views (e. g. about the fallibility of mathematics and about the independence of mathematical content from its formalized or axiomatized form) have prior examples in the history of mathematics. However, these alternatives should be rejected. Both the formation

13. In Lakatos' terminology as explained in Lakatos 1967, pp. $200 \mathrm{f}$. 
of Lakatos' philosophy of mathematics, and the rise of the most important ideas of (Szabó 1969) were taking place during a decade when Szabó and Lakatos could not meet personally: between 1957 and 1965. They exchanged letters infrequently during these years. I have not systematically studied this correspondence yet; however, it is clear that they were familiar with each other's works: read each other's papers but they could not discuss them in depth. Lakatos did not publish anything before his 1956 emigration in the field of their common interest, dialectics in mathematics; however, there are many traces of their common studies and planned common works in that area (hints in their letters, remembrances of other people). ${ }^{14}$

Szabó's first papers about Greek dialectics were written in the early fifties, but he elaborated the connection between dialectics and mathematics in a series of papers at the same time when Lakatos worked on his "Proofs and Refutations." Lakatos included in his book a reference to Szabó's "deiknymi" paper mentioned above (Szabó 1958), when he talked about thought-experiment "the most ancient pattern of mathematical proof" (Lakatos 1963-64, 14(53): 10, Lakatos 1976, p. 9). Lakatos used this pattern as the structure for his "Proofs and Refutations." Another, no less important reference by Lakatos to (Szabó 1960) is in a footnote to the question of refutability of hidden lemmas (Lakatos 1963-64, 14(55): 228 and Lakatos 1976, p. 49). Lakatos refers to Szabó's historical explanations according to which even the axioms and postulates of Euclidian geometry were regarded originally as principally refutable assumptions and not trivial truths as Aristotle regarded them. ${ }^{15}$ Lakatos was possibly influenced by Szabó's papers also in his other writings about mathematics. But it is

14. Szabó to Lakatos, $15^{\text {th }}$ Nov. 1957 (after complaints concerning his busyness): "If I have some spare time, I must devote it to our common studies. (But I didn't totally fall behind in this! I have just finished a paper "Die Grundlagen in der frühgiech. Math." [The foundations in early Greek mathematics]. . . . )" See further fn. 3., fn. 10.

15. The history of origin of (Szabó 1960) can be followed from his letters to Lakatos. As he writes on 15. Nov. 1957, he sent the "deiknymi"-paper to the great algebraist and historian of mathematics B. L. van der Waerden, who was the first to propose the idea that Zeno of Elea played a substantial role in the development of Greek mathematics (see van der Waerden 1940). On $24^{\text {th }}$ Sept. 1958 he gives an account about van der Waerden's answer from July 1958. "I can say I live morally by this letter since then." He quotes v. d. W.: "Your thesis that the mathematicians learnt indirect reasoning from the Eleats didn't absolutely convince me," but in spite of that, "I have read your paper with ascending admiration". Some weeks later van der Waerden answers to another manuscript (published later as [Szabó 1962]), Szabó quotes on $24^{\text {th }}$ Dec. 1958: "Your new explanation convinced me that your view about the influence of Eleatic philosophy on the foundation of mathematics is far better founded than I supposed originally" (van der Waerden in German). On $16^{\text {th }}$ Oct. Szabó tells Lakatos that van der Waerden proposed to the newly founded Archive for history of Exact Sciences that they publish (Szabó 1960). 
hardly probable (and cannot be supported by any evidence) that concerning the basic principles summarized in the previous paragraph, he could find something fundamentally new in them. It is much more probable that Lakatos could recognize the support and development of ideas they had in common during their studies and conversations. ${ }^{16}$

The key word describing their common ideas is "dialectics." But this term has more than one meaning and I am not sure they always understood it in the same way. Dialectics in the Marxist-Leninist sense was the intellectual weapon that Lakatos offered to Szabó at the very beginning of their acquaintance-Szabó remembered it later that he did not completely understand what Lakatos meant by this and that the idea was not very attractive to him either. He knew very well of course what dialectics meant for Plato, and his studies in the early fifties were directed to ancient dialectics in the original sense. ${ }^{17}$ He studied Hegelian and Marxian dialectics with Lakatos (from sources we do not know). Lakatos mentions Hegelian dialectics among the main sources of his philosophy. John Kadvany explains Lakatos' "Hegelianism" by surmising a parallel between Proofs and Refutations and Hegel's Phenomenology of Spirit and states that Lakatos' Hegelianism should be understood mainly as the view that the way of the mind to the recognition of itself leads over failures and errors, the way to the truth leads through falsities and mistakes. ${ }^{18}$ This sense of dialectics is not far from the sense in which dialectics played a decisive role in the development of Greek mathematics according to Szabó, but it is very far from the sense in which dialectics was the method of the official MarxistLeninist philosophy of the "socialist" countries. In the next section I elaborate on Szabó's analysis of Greek mathematics as a dialectical investigation from Zeno onwards.

\section{A Platonian, but not "Platonist" philosophy of mathematics}

Szabó's main work is devoted to the history of mathematics between Thales' and Pythagoras' age and Euclid's Elements. The book argues for some innovative and widely disputed claims about mathematical discoveries and conceptual developments of this period. But as this work is not of the "blind" sort of history (see epigraph), its content has an important philosophical aspect also. Szabó reconstructs (mainly from the dialogues of

16. As Szabó read a paper in the University of Krakow about his research, somebody remarked that his point resembled that of Lakatos. Szabó's answer was "No, Lakatos resembles me!" (I owe this story to Prof. Jan Wolenski.)

17. Passages like the introduction of (Szabó 1954a) with quotes from Lenin, where it is claimed that the dialectics of thought is a part of Hegel's and Lenin's general dialectics, can be understood only as concessions to the necessities of the communist era.

18. See (Kadvany 2001, pp. 30-43, 51-53). 
Plato) a philosophical interpretation of mathematics that is intended to be the original and authentic philosophy of the early Greek mathematicians. With respect to its source, this philosophy may be called Platonian; however, it is quite far from the view called Platonism in $20^{\text {th }}$ century philosophy of mathematics.

The historical claims of Szabós main work were sharply criticized and sometimes with good reason. I want neither to defend nor to attack any of its claims that belong to various individual mathematical discoveries. Both of the most intensely discussed questions are relevant to this investigation, but we don't have to decide whether Szabó was right or not.First is the question of priority: were indirect argumentation and deductive reasoning invented by (pre-Euclidean) mathematicians or by some philosophers (the Eleatics or Aristotle)?19 In this respect, I will focus on the consequences and the philosophical relevance of Szabó's position without taking sides.-The other question is the interpretation of the mathematical locus of Plato's Theaetetus. Do Theaetetus' words about the mathematics class of Theodorus report about the (first) discovery of the general theory of irrationals by himself, the genial young mathematician, ${ }^{20}$ or do they just report about the method of the good teacher Theodorus, who makes his students rediscover this theory?21 Our position regarding this alternative is a bit paradoxical: as we shall see, it is an important point concerning Szabó's Platonian philosophy (and its intellectual background) that proper learning of mathematics is rediscovery of mathematics; however, he could be wrong in his proposition that Theaet. 147D-148B should be read as speaking about a rediscovery and not about a discovery.

Szabó's reconstruction is directed mainly against Aristotle's interpretation of mathematics as a demonstrative science explained mainly in the Posterior Analytics ${ }^{22}$. Demonstrative science proves its theorems from unquestionable and primary arkhai (definitions, axioms and postulates) by means of logical deduction and owes its infallibility to the truth of the arkhai and to the reliability of the syllogism (see Posterior Analytics, I.5. [74b5-18]). This Aristotelian, infallibilist picture of mathematics re-

19. See Hintikka, Gruender and Agazzi 1980, especially the contributions of Hintikka, Berka and Knorr. But Szabó's claim concerning the priority of Eleatic dialectics has been criticized earlier by William Kneale and Paul Bernays (answering to Szabó 1967) in Lakatos 1967a.

20. This is the traditional interpretation defended against Szabó's attack (Burnyeat 1978).

21. This interpretation is elaborated in (Szabó 1969, pp. 69-94/Szabó 1978, p. 61-85). Szabó made his own philological analysis of mathematical terms.

22. Szabó's criticism of Aristotle is summarized in Szabó 1969, pp. 302-310./Szabó 1978, pp. 293-299. 
mains the ruling doctrine in philosophical thinking about mathematics perhaps until the last decades of the last century; moreover, theorems of mathematics become and remain examples for everlasting and indubitable truths. The development of mathematics from the middle of the $19^{\text {th }}$ century on puts in question this picture, but the first overall attempt to give an account about the fallibility of mathematics was done by Lakatos.

\subsection{Dialectics and the fallibility of mathematics}

Szabó bases the fallibility of (axiomatized, Euclidian) mathematics on the dialectical origins of the axiomatic method. Dialectics is to be understood here as the art of discussing controversial views and questions; it was practiced in Greek philosophy by the Sophists, by Socrates and also by some earlier thinkers. Aristotle calls Zeno of Elea "the father of dialectics" in this sense, but in his classification of argumentations, dialectical arguments are ranked second only, superseded by demonstrative argumentation, because the former sets out from just probable propositions (Topica, I.1. [100a29-34.]), or from questions proposed for discussion by the one or the other participant (Prior Analytics I. 1., 24a22-25). The first propositions from which dialectical argumentation sets out (without deciding in advance whether they are true or not) are called "hypotheses" in general; there are several expressions which refer to different sorts. Definitions (boroi) should be distinguished among dialectical hypotheses, but other hypotheses (or even hypotheses including definitions) are often called bomologema (agreement), aitema (literally "demanded [thing]", but this expression is translated in all translations of Euclid as "postulate"), and by various other names.

One of Szabó's important arguments for the dialectical origin of the method of mathematics is that all the expressions for the arkhai (first principles, i.e. definitions, axioms and postulates) come from the special terminology of dialectics. This fact seems to be in opposition to Aristotle's view that the arkhai are true and primary propositions.

On the other hand, Plato puts dialectics in first place among knowledge-gaining practices, and in his classification mathematics gets second rank only, because mathematicians "assume the odd and the even, the figures, . . . as if they were known for them. These they make their hypotheses and do not deem it necessary to give any account of them either to themselves or to others, as if they were clear to all." 23 The Platonic Socrates reproaches the mathematicians here with forgetting about the dialectical character of hypotheses and treating them as secure foundations. It

23. Republic 510c, trans. Grube, slightly modified on the basis of the original. Note that Socrates mentions concepts and not theorems as items supposed by mathematicians. 
may seem that even according to Plato, Aristotle's view agrees with the mathematician's view about the character of first hypotheses or arkhai. But Szabó's claim is different. He presents the axiomatization of Greek mathematics as a one-and-a-half century long process, which originates directly from Zenonian dialectics (Szabó 1969/1978, ch. 3.5, 3.6.). If Socrates suggests in the quoted sentences that the primary concepts and propositions of mathematics are just hypotheses accepted in order to investigate their consequences but in principle they are open to refutation, he should represent the authentic view of the originators of deductive mathematics against Plato's contemporaries who evidently forgot it.

The superiority of dialectics over mathematics is due to the feature that dialectics investigates consequences of the hypotheses not only in order to gain (conditional) knowledge dependent on their truth, but also in order to judge the hypotheses themselves. If a hypothesis leads to unacceptable, especially to contradictory consequences, then it should be rejected. We cannot set out from true and absolutely reliable arkhai; everything is open to revision and rejection. ${ }^{24}$ In practice, we can never be sure about any result of the dialectical investigation, we cannot be sure that it cannot be refuted later. Somewhat after the passage quoted above, Socrates sketches a picture of the process and the final goal of dialectical investigation, which suggests the hope that dialectics can sometimes reveal the fundamental truth (that is the knowledge of the Good) by successive reduction of our hypotheses to something more fundamental (511b-c). However this hope does not give us the right to declare at some stage that we have reached the truth; investigations can always be continued and the continuation always involves the possibility of rejection. ${ }^{25}$

24. At a place in the Republic, (436e-437a) even the principle of the exclusion of opposites is declared as a hypothesis that should be rejected if further investigation refutes it.

25. There is an important parallel passage that Szabó doesn't analyze: Phaedo 107a-b, where Socrates closes the argument for the immortality of the soul and asks whether anybody has some further objection. Simmias answers:

Well no, nor have I any further ground for doubt myself, as far as the argument goes; though in view of the size of the subject under discussion . . . I'm bound to retain some doubt in my mind about what's been said.

And Socrates praises him for doubting in his own argument, moreover, he generalizes the point:

Not only that, Simmias, what you say is right, so the initial hypotheses, even if they're acceptable to you people, should still be examined more clearly: if you analyze them adequately, you will, I believe, follow the argument to the furthest point to which man can follow it up; and if you get that clear, you'll seek nothing further (trans. Gallop). 


\subsection{Mathematics, dialectics and the Zenonian "Crisis of foundations" 26}

So our investigations do not begin with the truth; they strive to reach the truth. The starting point should always be a problem. According to Szabó's analysis, it is in the history of philosophy that we can find the problems, which induced the transformation of archaic, intuitive Greek mathematics into Euclidian axiomatized mathematics: they are Zeno of Elea's paradoxes. Zeno's master, Parmenides, had claimed in his poem that the Being is one and unmovable, contrary to the false witnesses of our eyes and ears about beings. In Plato's Parmenides the young Socrates discovers the "secret" goal of Zeno's book: he defends his master's views by his arguments that deduce contradictions from the existence of plurality. Zeno answers that Socrates correctly interprets his book as a whole; he refutes people who find Parmenides' claim laughable and shows that their views lead to even more ridiculous consequences (Parmenides 127e-128c).

Eleatic philosophy must have influenced the formation of deductive mathematics in a threefold way. (a) The first part of the influence is a general philosophical view, (b) the second part consists of some special problems that early Greek mathematics had to face and (c) the third is the dialectical method itself that indicated the way to solving these problems.

(a) On the general philosophical level, Szabó attributes to axiomatized mathematics, as known from Euclid, a general tendency which he calls "anti-empirical and hostile to intuition" (Szabó 1969, on several places) and which is manifested in the fact that figures-although present in the Elements-play no role in the demonstrations. This tendency must have been contrary to the views and methods of the first Greek mathematicians-Thales, the early Pythagoreans and perhaps othersthat are preserved e.g. in the Greek terminus technicus for mathematical demonstration: deiknymi. ${ }^{27}$

(b) These views and methods make use of motion and of plurality in a naive way, therefore, Zeno's paradoxes should be regarded as serious objections to mathematicians using them (as against anybody who "do [es] not deem it necessary to give any account of them either to themselves or to others, as if they were clear to all"). In some of Euclid's axioms and postulates Szabó sees direct answers to problems exposed in Zeno's antinomies. Even the division of basic hypotheses into definitions, postulates and axi-

26. Van der Waerden's expression in his (1940), with allusion to the "crisis of foundations" at the beginning of the $20^{\text {th }}$ century.

27. Szabó 1969, pp. 246-250/Szabó 1978, pp. 185-199, cf. Szabó 1958. More about Greek mathematics before this tendency and the beginnings of axiomatization see below in $\$ 3.4$. 
oms should be a consequence of this connection: the postulates (especially the first three) are answers to paradoxes of motion (Szabó 1969, pp. 366378/Szabó 1978, pp. 273-279), the axioms answer to paradoxes of plurality and divisibility (ibid. pp. 394-416/pp. 291-299).

In what sense does Euclid's first postulate: "Let us postulate [i.e. demand] the following: ... [ [t]o draw a straight line from any point to any point" (trans. Heath) give an answer to Zeno's paradoxes of motion? According to Szabó it does because it restricts the way we may refer to motions in our demonstration. As a consequence of Zeno's paradoxes, we should eliminate motion in general from our (geometrical) argumentations, but by postulates 1-3 we assume the existence of some restricted sorts of motion. We don't accept them, because according of our senses and impressions they are true. Maybe they are, but we have a stronger reason than the witness of our fallible senses to accept them: they have not led to contradiction yet.

(c) Of course, even this reason is not strong enough to believe that they are final and irrefutable truths. According to the dialectical interpretation of axiomatic geometry, we are not even committed to the truth of the basic hypotheses. We demand from our opponent to accept them in order to investigate its consequences together.

\subsection{Indirect demonstration and its significance}

The third factor in the influence of Eleatic philosophy in the formation of deductive mathematics must have been the method of indirect argumentation. The oldest text we know that uses this sort of argumentation was Parmenides' poem, where the author proved the immovability, homogeneity, timelessness etc. of the one Being by refuting the opposite propositions (Parmenides, fragment 8. 5-49). As we have seen, Zeno's set of paradoxes as a whole can be read as an indirect refutation of the possibility of motion and plurality; but the arguments for the individual paradoxes contain more than one sophisticated application of this method.

Szabó sees in the discovery of indirect argumentation the turning point of the transformation that took place in mathematics between Thales and Euclid. This discovery must have forced the break away from intuitive evidence. As we shall see in the next paragraph, archaic Greek mathematics must have been argumentative too, but it didn't distinguish between propositions proved earlier and propositions accepted as evident on the basis of our intuition and experience-just as we do not distinguish these in everyday argumentation. In that way of argumentation, we progress from one true proposition to another, without too much concern to specify the origin of these propositions. On the other hand, if we prove that the side 
and the diagonal of the square have no common measure, we may use figures to illustrate our argumentation, to show how does the usual process of searching for a common measure, the method of mutual subtraction work, but at some stage we cannot avoid using a supposition that cannot be illustrated on the figure because it is false. We cannot avoid reaching a point where we must say something like this: "If there were some line segment E which would be the (largest) common measure of the side and the diagonal of the original square, then there would be another line segment whose length is not 0 , smaller than the length of $E$ and a multiple of the length of E." This step cannot be made intuitive for a simple reason. We can't draw these line segments into our figure, because there are no such segments. As Szabó establishes, “ . . . diagrams cannot illustrate the most important part of the argument.” (Szabó 1969, p. 282/ Szabó 1978, p. 213). It was a widely held view concerning the turn of Greek mathematics we speak about that the discovery of incommensurability was the starting point of it. Szabó argues in detail that on the contrary, this discovery presupposes the conscious and sophisticated use of indirect argumentation. (Szabó 1969, pp. 111-119/Szabó 1978, pp. 85-91).

As we have seen above, the way of argumentation in deductive mathematics should be understood in general as hypothetical; i.e., the mathematician demonstrates only that if his first hypotheses are true, then his theorems also hold. Hypothetical argumentation sets out from premises whose truth is at least uncertain and indirect argumentation is a special case of it, where (at least one of) the initial premise(s) is false and the argumentation has to prove this fact. Hypothetical argumentation is the characteristic way of argumentation in dialectics, and this feature is inberited by axiomatized mathematics according to Szabó's analysis. In addition to pointing out the dialectical origin of the terminology in the foundations of mathematics, Szabó refers to the observation that the Elements use the method of indirect argumentation even more often than it is needed: Several theorems that have a more or less obvious direct demonstration are proved in the indirect way (Szabó 1969, pp. 326328/Szabó 1978, pp. 320-322). This methodological feature is connected with the turning away from intuition, and this latter tendency manifests itself in the fact that survived manuscripts contain figures that show and illustrate nothing from the theorem or its demonstration next to which they are drawn in the text. Such figures should be remainders of an earlier, intuitive stage of mathematical method.

\subsection{Mathematics before axiomatization}

Greek mathematics was clearly not born as a deductive-axiomatic science. The question for Szabó (as well as for the earlier research) was this: how and why did the idea and the realization of deductive-axiomatic mathe- 
matics develop and what antecedents did it have? The most widespread assumption in the literature was that Greek mathematics originated from a transmission from earlier (Egyptian, Babylonian) cultures: the Greeks further developed Egyptian geometry and geometrized Babylonian algebra; some Marxists tried to explain the development of Greek mathematics by the needs of trade and industry. ${ }^{28}$ Such claims of transmission give no explanation of the change of method, and Szabó concentrates on the method itself as the substantial novelty produced by Greek mathematics of $5-4^{\text {th }}$ century B.C. ${ }^{29}$

In order to discover the early history of Greek mathematics and its progress toward axiomatization, Szabó investigated evidence about other sciences of the same period-mainly astronomy and musical theory-and the reports about Greek mathematics earlier than Eleatic philosophy. ${ }^{30} \mathrm{He}$ supported the view that the mathematics of Thales and his contemporaries was basically intuitive: they used figures, configurations of calculating pebbles (psephoi) etc. to persuade people about arithmetical and geometrical propositions. This archaic, intuitive mathematics must have been different from the mathematics of other cultures in that it formulated general propositions and supported them by arguments, but it was different from Euclidian mathematics in that it did not make clear the difference between the intuitively obvious and the logically proven. There are many terminological remainders of this stage (the verb deiknymi [to show] was mentioned earlier, but the term "square number" and its Greek original (tetragonos arithmos), for instance, come from the illustrations of numbers by pebbles). The sources - mainly testimonies from late antiquityreveal that this mathematics could reach many results, which were proven in the strict deductive way substantially later. Therefore, the victory of the new method cannot be explained by its effectiveness; its superiority rests in the fact that it solved the "Crisis of foundations."

The investigations into early Greek musical theory and astronomy and their connections with mathematics display the process of the formation of mathematical concepts that are inherited by axiomatic mathematics. The main aspect of continuity between archaic, intuitive and classical, de-

28. Alexits and Fenyo 1948 popularized this latter view in Hungary; Szabó made some ironical and furious remarks on it in his Hungarian papers.

29. There is one possible external factor in the development of methods of argumentation, which could perhaps contribute to the growing presence of systematic argumentation in philosophy and in mathematics, and this is the juristic practice in the Greek polis. Szabó never investigated this question.

30. His results concerning this question are contained mainly not in Szabó 1969, but in his later book (Szabó 1994). 
ductive mathematics is not mainly the problems and theorems, but the concepts, which remain the same.

\section{Mathematicians and intellectual life in Hungary}

As mentioned above, Lakatos' connection with Szabó dates from his student days when he took Szabó's Plato seminar in Debrecen, continued in the years after World War II and in 1953-56 in Budapest, and followed by correspondence after 1957 (see footnotes 8-14 above). It is evident that the intellectual contact between Szabó and Lakatos did not take place in an intellectual vacuum; they were both participants in the intellectual life of mid-twentieth century Hungary. In particular, they were in contact with some excellent mathematicians: with a school of mathematics that played a considerable role in twentieth century mathematics inside and outside Hungary. Representative figures of this school were, among others, Georg Pólya, John von Neumann, Pál Erdos, László Kalmár, and Alfréd Rényi. Further research may uncover what ideas in this circle could have influenced Lakatos and Szabó; in this section, I will briefly mention some questions and persons that may be interesting in this connection.

First of all, the problem of mathematics education deserves our attention. In Lakatos' Proofs and Refutations, classes of mathematics model the history of mathematics, and in these classes, the concept of polyhedron and the theorem of polyhedra is developed in the dialectical way: both teacher and students raise objections, provide counterexamples, refute the earlier results and propose new solutions to the problems raised. They all discover the geometry of polyhedra. This discovery is the task of mathematicians and the task of mathematics education, and the task of a real apprenticeship in mathematics as well. Lakatos' whole construction is based on the tacit assumption that mathematical research and education/ learning of mathematics are not substantially different processes.

Szabó bases his analysis of "the mathematics class of Theodorus" (mentioned in section 3.) on this idea. This point is important not only because — if Szabó was right — the theory of irrationals was discovered much earlier than it is generally thought, but because it is characteristic of the methodology of dialectical mathematics. As the famous slave scene of Plato's Meno shows, anybody can discover the answer to problems such as the doubling of a square; the teacher of mathematics has to help the student to find the way of discovery and to refute his false answers to the problem; however, he must not (cannot even) find the right answer for him. The mathematician, the first discoverer, differs from the student only in that he does not have this help; he learns mathematics all by himself.

This is an idea that was common and important for many mathematicians of last-century Hungary. Tamás Varga, a colleague in the Rényi In- 
stitute and a friend of both Lakatos and Szabó, has attempted a reform of mathematics education from the 1960's based on this idea. Among the main supporters of his "new mathematics" were László Kalmár, Alfréd Rényi and Rózsa Péter. But amongst people who left Hungary, Pólya’s heuristics and his work in mathematics education, and Zoltán P. Dienes' work on the same area (see Dienes 1961) were also based on this idea. It fits into the worldwide tendency what was called "reform pedagogy" in Hungary, that was based on the (moral and intellectual) autonomy of the student. Reform pedagogy regarded the student as a partner of the teacher and not just as an object of his work, unlike the Prussian style education, which had (and continues to have) an overwhelming influence in Hungarian education. Perhaps the most influential representative of reform pedagogy was Sándor Karácsony, professor of pedagogy in the University of Debrecen and center of an intellectual circle in the short-lived democracy of Hungary after World War II. Although he was not a mathematician (his main interests were grammar, psychology and theology), some important mathematicians, including Kalmár, Varga and Péter, belonged to his circle. ${ }^{31}$ Szabó and Lakatos did not belong to the Karácsony circle, but they both had close personal contact with him. The part of the idea that does not belong to education but to mathematical research-i.e. that the mathematician doing research work learns the mathematics as well-was developed in a beautiful way in the popularizing book of Rózsa Péter "Playing with Infinity" (Péter 1945).

The philosophical ideas of the mathematicians mentioned also deserve our attention. ${ }^{32}$ Kalmár certainly belonged to the first mathematicians who rejected the dogma of the infallibility of mathematics. His address on the 1965 London Colloquium in the Philosophy of Science (Kalmár 1967) has a special interest for us, because he argues in favor of an empiricist view of mathematics using Szabó's historical results, and in his own answer (Lakatos 1976) Lakatos states that Kalmár's views are closely related to his own. On the other hand, Rényi’s brilliant pseudo-Platonic dialogues on mathematics (Rényi 1965) represent another sort of mathematical philosophy. As Rényi writes in his postscript to the Hungarian volume, he has been clearly influenced by Szabó's analysis of the method of Platonic

31. About Lakatos, Kalmár, Varga and the Karácsony circle see (Gurka 2006).

32. They belonged to a mathematical tradition in Hungary that started flourishing sometimes around the turn of 19-20th century. Some representatives of this tradition (Pólya, Erdos, Neumann) did leave Hungary, but many other people who won worldwide reputation did not. From its foundation in 1950, the Rényi Institute has been the main place where this cultural tradition continued. Its history is not yet elaborated; but interest in mathematics education and in philosophy appear to be common features of its representatives. 
dialogues and chose the dialogue form to expound views about the nature of mathematics, which is especially suitable to the subject. However, the Socrates of the first dialogue (the mouthpiece of the author) speaks as an Aristotelian infallibilist. ${ }^{33}$ So it seems that in this intellectual circle there were different opinions in this respect: fallibilists like Lakatos, Szabó, Kalmár on the one side, infallibilists like Pólya ${ }^{34}$ and Rényi on the other. The exploration of this question (and other questions that could emerge concerning the views of the mathematicians mentioned in this section) goes beyond the scope of this paper.

\section{References}

Alexits, György and Fenyo, István. 1948. Mathematics and dialectical materialism (Matematika és dialektikus materializmus). Budapest: Szikra.

Burnyeat, Miles. 1978. “The Philosophical Sense of Theaetetus' Mathematics." Isis 69: 489-515.

Dienes, Zoltán P. 1961. Building up Mathematics. London: Hutchinson.

Gurka, Dezso. 2006. “A Missing Link: The Influence of László Kalmár’s Empirical View on Lakatos' Philosophy of Mathematics." Perspectives on Science, this issue.

Hintikka, Jaako, David Gruender and Evandro Agazzi. 1980. Theory Change, Ancient Axiomatics, and Galileo's Methodology. Proceedings of the 1978 Pisa Conference on History and Philosopby of Science vol. 1. Dordrecht: Reidel.

Kadvany, John. 2001. Imre Lakatos and the Guises of Reason. DurhamLondon: Duke University Press.

Kalmár, László. 1967. "Foundations of Mathematics: Whither Now?” in: Lakatos 1967a, pp. 186-194.

-1974. Foundations of Mathematics (A matematika alapjai). Ninth edition, four volumes, Budapest: Tankönyvkiadó.

Kutrovátz, Gábor. 2001. “Imre Lakatos' Hungarian Dissertation. A documentation.”, in: Kampis, G—L. Kvasz-M. Stöltzner (eds.): Appraising Lakatos. Dordrecht: Kluwer.

33. This dialogue, written originally in Hungarian, was read as an after-dinner speech to the American Physical Society and Canadian Association of Physicists in Edmonton and published in the December 1964 issue of Physics Today. Lakatos' copy, preserved in the Lakatos Archive of the London School of Economics, contains some "horrified annotations" to the passages expressing Rényi's infallibilism (see pp. 8. and 17. of the Web English version of (Rényi 1965); kind information about Lakatos' copy and words by Alex Bellamy).

34. Pólya's several writings about heuristics investigate methods of discovery and problem-solving in mathematics that are not infallible; but he has opposed the ways of discovery that are fallible to the way of demonstration that is infallible. A concise formulation of this contrast: "Demonstrative reasoning is safe, beyond controversy and final. Plausibe reasoning is hazardous, controversial and provisional." (Pólya 1954, p. v). 
Lakatos, Imre. 1963-64. "Proofs and Refutations" I-IV. The British Journal for the Philosophy of Science $14 \mathrm{nn}$. 53-56.

- 1967a ed. Problems in the Philosophy of Mathematics. Imre Lakatos. Amsterdam: North-Holland Publishing Co.

- 1967b. "The renaissance of empircism in the recent philosophy of mathematics?", in: Lakatos 1967a, pp. 199-202.

- 1976: Proofs and Refutations. The logic of Mathematical Discovery. John Worall and Elie Zahar (eds). Cambridge: Cambridge University Press.

- 1978. Mathematics, Science and Epistemology. Philosophical Papers vol. 2. Cambridge: Cambridge University Press.

Motterlini, Matteo. 1999 (ed.). For and Against Method. Chicago: Chicago University Press.

Péter, Rózsa. 1945. Játék a végtelennel. Budapest: Dante Könyvkiadó. English edition: Playing with Infinity, London: G. Bell and Sons, 1961.

Pólya, György. 1945/1969. How to Solve It? (A gondolkodás iskolája). Second Hungarian edition, transl. Imre Lakatos, Gondolat: Budapest. (Original edition: Princeton: Princeton University Press.)

-1954. Mathematics and Plausible Reasoning. Princeton: Princeton University Press.

-1962. Mathematical Discovery. New York: John Wiley \& Sons.

Pólya, Georg and Gábor Szego. 1998: Problems and Theorems in Analysis III. New York: Springer. Original German edition: 1927, 1930.

Reinhardt, Karl. 1916. Parmenides und die Geschichte der Griechischen Philosophie. Bonn.

Rényi, Alfréd. 1965. Dialógusok a matematikáról. Budapest: Akadémiai Kiadó. English edition: Dialogues on Mathematics. San Francisco: Holden Day, 1967. A new English version of the first dialogue: "Mathematics. A Socratic dialogue by Alfred Rényi." Websource: www.bergen.org/ update/Math.pdf.

Szabó, Árpád. 1953. "Towards a History of Greek Dialectics" (Zur Geschichte der griechischen Dialektik), Acta Antiqua Academiae Scientiarum Hungaricae I: 377-410.

- 1954a. "On the History of the Dialectics of Thought" (Zur Geschichte der Dialektik des Denkens), Acta Antiqua Academiae Scientiarum Hungaricae II: 17-62.

1954b. "Towards an Understanding of the Eleatics" (Zum Verständnis der Eleaten), Acta Antiqua Academiae Scientiarum Hungaricae II: $243-289$.

- 1958. "Deiknymi, as a mathematical expression for to prove" (Deiknymi, als mathematischer Terminus für beweisen) Maia 10:106131. 
. 1960. "Beginnings of Euclidian Axiomatics" (Anfänge des Euklidischen Axiomensystems). Archive for the History of Exact Sciences I: 37-106.

1962. "The Oldest Attempt to a Definitional-Axiomatic Foundation of Mathematics" (Der ältesteVersuch einer definitorischaxiomatischen Grundlegung der Mathematik). Osiris 14: 308-369.

- 1967: "Greek dialectic and Euclid's axiomatics", in: Lakatos 1967a, pp. 1-8.

-1969. Anfänge der griechischen Mathematik. München: R. Oldenbourg-Budapest: Akadémiai Kiadó. 1978 English edition: The Beginnings of Greek Mathematics. Translation by Tony Ungar. Dordrecht: Reidel.

1994. The Development of Greek Mathematics (Die Entfaltung der griechischen Mathematik). Mannheim etc.: B. I. Wissenschaftsverlag. van der Waerden, Baartel Leendert. 1940. "Zeno and the Crisis of Foundations of Greek Mathematics" (Zeno und die Grundlagenkrise der griechischen Mathematik). Mathematische Annalen 117:141-161. 
Copyright of Perspectives on Science is the property of MIT Press and its content may not be copied or emailed to multiple sites or posted to a listserv without the copyright holder's express written permission. However, users may print, download, or email articles for individual use. 